\title{
Real-time implementation of SMC-PID for Magnetic Levitation System
}

\author{
A VIMALA STARBINO*(D) and S SATHIYAVATHI \\ Department of Mechatronics Engineering, Kongu Engineering College (Autonomous), Erode, India \\ e-mail: starbino2013@gmail.com; sathi.ed@gmail.com
}

MS received 12 February 2018; revised 26 December 2018; accepted 3 January 2019; published online 20 April 2019

\begin{abstract}
Magnetic levitation is significant in almost all arenas of engineering. This principle is used to levitate objects such as a bullet train, flywheel, etc. This paper presents an experimental set-up of Magnetic Levitation System (MLS) in which a ball is levitated to a desired position and is sustained at a desired level for a stipulated time. The ball position is measured using an optoelectronic sensor and a controller is used to determine the time span of the ball at desired heights. To achieve this, a Sliding Mode Controller (SMC) is designed in such a way so as to regulate the current, which in turn controls the position through an electromagnet. Real-time observations of such ball positions have been recorded and compared to those of conventional PID (Proportional Integral Derivative) and robust SMC. Disturbance rejection, servo operation and set point tracking have also been tested and verified for the same. The outcome of such results processed through MATLAB proves that SMC's performance is predominant over other controllers.
\end{abstract}

Keywords. Sliding Mode Control (SMC); magnetic levitation (maglev); Proportional Integral Derivative (PID); experimental; response; robustness.

\section{Introduction}

The research works in magnetic levitation (maglev) technology have been undertaken substantially due to its high nonlinearities and unstable performance [1]. Maglev system is a nonlinear, open-loop unstable and time-varying dynamic system, in which the object is levitated under the influence of the interaction between the object and the applied magnetic field [2]. This concept is greatly appreciated as it has got wider applications in major fields. Using maglev, miniature objects are elevated to different positions by a micro-robot and the objects are assembled in hazardous zones [3]. Also, series electromagnets are combined in an active magnetic bearing system to levitate objects to ensure noncontact motion and reduction of power loss; hence this concept is applied in businesses, medical fields, etc. [4]. In addition to this, a magnetically levitated table is used to automate drilling of centred micro-holes, which is usually done manually by skilled craftsmen [5]. Applications of maglev is extended further into a liquid hydrogen tank, where connection between inner and outer tanks is made through permanent support, which produces high evaporation losses as the support produces detrimental heat

*For correspondence input. This can be eliminated by the levitation of inner tank with the help of superconductors; hence, it is free from fixed fixtures [6]. To deposit a thin coating on the metal foils, high deposition rate is essential. It can be achieved using conductive materials exposed to high-frequency electromagnetic fields. Magnetic levitation technique is used to lift the conductive material to coat at high physical vapour deposition rate [7]. The effectiveness of maglev technology relies on the levitation forces produced by the permanent magnets for all of its applications. Hence, control of force is essential depending on shape, size and magnetic properties of permanent magnets and also its superconducting sample [8].

This system generates (a) propulsion force, (b) levitation force and (c) guidance force. Factor of dependence on each force is of high degree and hence this system requires a nonlinear controller to control the forces [9]. A closed-loop control system is essential to control the forces by configuring the electromagnets and also to stabilize the suspended magnetic object at desired locations. A mathematical model is brought into play to design a feedback control system, on the basis of which appropriate controllers can be selected to achieve excellent performance to stabilize the magnetic object [8].

Initially, various design strategies were deployed using linearization concept for the nonlinear behaviour of maglev, which led to the development of conventional controllers like Proportional Integral Derivative (PID), but 
it failed to achieve tracking of the object effectively; hence, nonlinear controllers are significant [10]. Different advanced control schemes have been proposed by various researchers for maglev to minimize the problem of tracking, settling time, modelling inaccuracy, positioning, etc. For example, as regards the pivot point method, time consumption is eliminated by solving differential equations of the system. A direct fast model is developed based on the geometry of electromagnet and its magnetic property. This is formulated to increase the accuracy of the positioning of the objects. Further, settling time is improved along with enhanced tracking; however, this model is dedicated for particular applications [11]. Even though a PID controller is a versatile controller for all cases, it cannot perform well against some nonlinearities; to control such nonlinearity, PIDs with some advanced controllers have been designed. One such hybrid model used is an IMC-based PID controller, in which an internal model is developed exactly similar to the system; as a result, the response shows reduced time in initial overshoot and settling time. However this method involves tuning for the time domain specifications like (controller gain $K_{c}$, integral time $T_{i}$, derivative time $T_{d}$ and tuning parameter $\lambda$ ) [12].

Another hybrid model fuzzy-PID controller is designed to stabilize the equilibrium point of maglev vehicle suspension system, which is verified by both simulation and experimentation [13]. A robust controller is designed using mathematical modelling by taking into account parametric uncertainties and unknown disturbances. As a result, improved time delay is proved through simulation [14]. A fractional order controller with special tuning method has been experimented and it has been proved that it has better performance than PID controller [15]. In addition to this, design of fractional order controller is enhanced by incorporating fractional calculus directly on the nonlinear dynamics of the system and the system performance is improved in terms of increased robustness [16]. Despite advanced control schemes producing best performance for nonlinear systems, the necessity for such schemes is the necessity of an exact model of the plant. Hence the controllers have to be designed to consider modelling inaccuracies. One such controller is Sliding Mode Controller (SMC)-PID, which assures better performance given the modelling and parametric uncertainties and unknown disturbances [16].

In this paper, a prototype of maglev is experimented; a mathematical model is developed for such a system; SMC-PID is designed and is incorporated with the system. Various levitation positions are verified with both SMC-PID and PID, and response is recorded. The paper is organized as follows. Section 1 is as above. In section 2, mathematical modelling of Magnetic Levitation System (MLS) is briefly explained. In section 3, SMC and PID designs are explained. In section 4 , step responses of experimental results for various levitation positions are presented graphically. In sections 5 and 6, discussion and conclusion about the system and controllers are explained, respectively.

\section{Mathematical modelling of the process}

The experimental set-up in figure 1 is simple in construction and very much useful in designing different controllers and also in educating engineering graduates as maglev is a challenging nonlinear plant with wide application areas [17]. In this set-up the steel ball position is measured using a LED-optoelectronic sensor and the measured signal is amplified. An analogue control module compares the measured signal to that of the desired position to actuate the ball position towards the set point. This actuation is achieved by controlling the electric current that is passed to the electromagnet.

To position the steel ball, a closed-loop control system is designed using mathematical modelling. A few assumptions are made to obtain the mathematical modelling of MLS using ball kinematics and differential equations. These assumptions are the following: (a) magnetic flux leak, (b) edge effect and (c) reluctance between the ball and the electromagnet is nil. Also, magnetic force is concentrated towards the centre of the ball. The system is summarized with the following equations:

$$
\begin{gathered}
m \frac{d^{2} x(t)}{d t^{2}}=F(i, x)+m g \\
F(i, x)=K\left(\frac{i}{x}\right)^{2} \\
m g+F\left(i_{0}, x_{0}\right)=0
\end{gathered}
$$

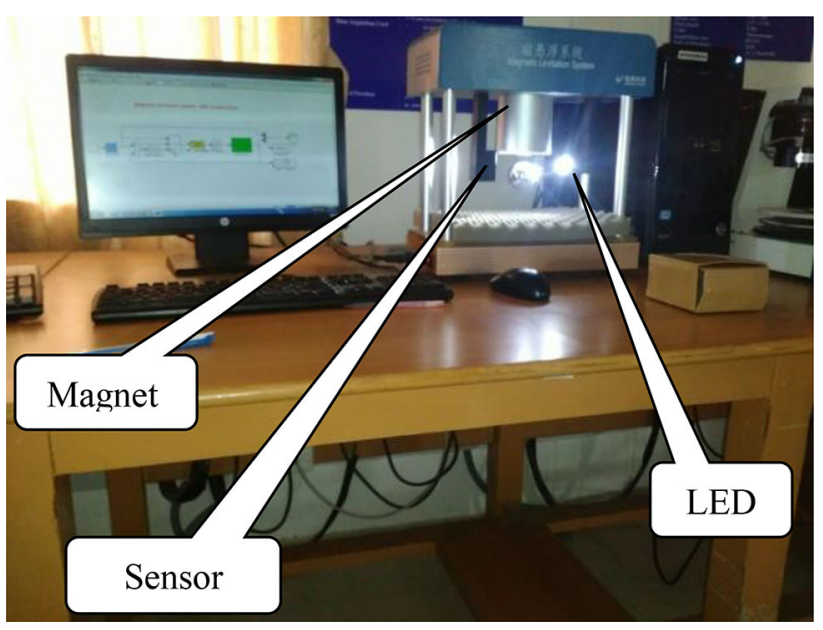

Figure 1. Experimental set-up of MLS. 
where $x$ is the air gap between ball centroid and magnetic pore, $\mathrm{m} ; i$ is the instantaneous current in the coil, A; $F(i, x)$ is the magnetic force, $\mathrm{N} ; m$ is steel ball mass, $\mathrm{kg} ; g$ is acceleration of gravity, $\mathrm{m} / \mathrm{s}^{2} ; F\left(i_{0}, x_{0}\right)$ is the magnetic force equal to ball gravity force, $\mathrm{N} ; i_{0}$ and $x_{0}$ are the balancing current and air gap at equilibrium (acceleration $=0$ ), respectively.

The relationship between magnetic force $F$, instantaneous current $i$ and air gap $x$ is nonlinear and hence magnetic force is linearized using Taylor's expansion:

$$
\begin{gathered}
F(i, x)=K_{i} i+K_{x} x+F\left(i_{0}, x_{0}\right), \\
K_{i}=F_{i}\left(i_{0}, x_{0}\right)=\frac{2 K i_{0}}{x_{0}^{2}}, \\
K_{x}=F_{x}\left(i_{0}, x_{0}\right)=\frac{-2 K i_{0}^{2}}{x_{0}^{3}} .
\end{gathered}
$$

$K_{i}$ and $K_{x}$ are power amplifier gain. (1) is resolved after substituting (2)-(6):

$$
m \frac{d^{2} x}{d t^{2}}=\frac{2 K i_{0}}{x_{0}^{2}} i-\frac{2 K i_{0}^{2}}{x_{0}^{3}} x .
$$

By solving (7), the system open-loop transfer function is derived as

$$
G(s)=\frac{x(s)}{i(s)}=\frac{-1}{-\left(\frac{m x_{0}^{2} i_{0}}{2 K i_{0}^{2}}\right) s^{2}-\frac{i_{0}}{x_{0}}} .
$$

Input variable of the system control model is defined as the input voltage $U_{\text {in }}(s)$ of the voltage-current power amplifier, and output variable as output voltage $U_{\text {out }}(s)$ of the processing circuit.

Transfer function of the voltage-current amplifier is

$$
A(s)=\frac{i(s)}{U_{\text {in }}(s)}=\frac{1}{K_{a}\left(1+T_{a} s\right)}
$$

where $K_{a}$ is power amplifier gain $=5.8929 ; T_{a}$ is time constant lag, which is very small; hence it is neglected.

$$
U_{\text {in }}(s)=K_{a} i(s) .
$$

The output voltage $U_{\text {out }}(s)$ of the processing circuit is given as

$$
U_{\text {out }}(s)=K_{s} x(s)
$$

where $K_{s}$, the power amplifier gain, is 458.71 .

Combining (9) and (10), the system transfer function is obtained as follows:

$$
G_{o}(s)=\frac{U_{\text {out }}(s)}{U_{\text {in }}(s)}=\frac{K_{s} x(s)}{K_{a} i(s)}=\frac{-\left(\frac{K_{s}}{K_{a}}\right)}{\frac{i_{0}}{2 g} s^{2}-\frac{i_{0}}{x_{0}}}
$$

where $m g=-K\left(\frac{i_{0}^{2}}{x_{0}^{2}}\right)$.

The system state equations are as follows:

$$
\begin{gathered}
\left(\begin{array}{c}
\dot{x}_{1} \\
\dot{x}_{2}
\end{array}\right)=\left(\begin{array}{cc}
0 & 1 \\
\frac{2 g}{x_{0}} & 0
\end{array}\right)\left(\begin{array}{l}
x_{1} \\
x_{2}
\end{array}\right)+\left(\begin{array}{c}
0 \\
-\frac{2 g \cdot K_{s}}{i_{0} \cdot K_{a}}
\end{array}\right) U_{\text {in }}, \\
\left(\begin{array}{c}
\dot{x}_{1} \\
\dot{x}_{2}
\end{array}\right)=\left(\begin{array}{cc}
0 & 1 \\
981.511 & 0
\end{array}\right)\left(\begin{array}{l}
x_{1} \\
x_{2}
\end{array}\right)+\left(\begin{array}{c}
0 \\
2502.96
\end{array}\right) U_{\text {in }}, \\
\dot{X}=A X+B U_{\text {in }} \\
y=[10]\left(\begin{array}{l}
x_{1} \\
x_{2}
\end{array}\right)=C X .
\end{gathered}
$$

Transfer function derived from state model is given by

$$
\begin{gathered}
G_{o}(s)=C(s I-A)^{-1} B \\
G_{0}(s)=\frac{2502.96}{s^{2}-981.511}=\frac{c}{s^{2}-a_{0}}
\end{gathered}
$$

where $c=\frac{2 g K_{s}}{i_{0} K_{a}}=2502.96$ and $a_{0}=\frac{2 g}{x_{0}}=981.511$.

\section{Controller design}

\subsection{PID controller}

For industrial process control, PID controllers have broader range of applications in almost all sectors of industrial automation. It competes with advanced control strategies but suffers from certain drawbacks. One such drawback is the following: nonlinear systems use PID with system linearization. The significance of robust controller is realized only when it is compared with the conventional controllers.

From the transfer function (14), the system parameters are identified as follows:

$$
\begin{gathered}
c=2502.96 ; a_{0}=981.511 ; \\
a=\sqrt{a_{0}}=\sqrt{981.511}=31.329 .
\end{gathered}
$$

With reference to [18], PID controller parameters $K_{p}, K_{I}, K_{D}$, namely proportional, integral and derivative gains, are found, respectively. The tuning rules are based on the assumption that the closed-loop poles are located in left hand side of the complex plane. Therefore the tuning rules are derived from the underdamped response, which ensures left hand side pole location and stability.

$$
\begin{array}{r}
K_{p}=\frac{3 a^{2}+a_{0}}{c}=1.568 ; K_{I}=\frac{a^{3}}{c}=12.39 ; \\
K_{D}=\frac{3 a}{c}=0.0372 .
\end{array}
$$




\section{$3.2 S M C$}

It is one of the robust controllers to control nonlinear systems. It has excellent disturbance rejection and set point tracking and in turn achieves good regulatory and servo response. Deciding appropriate sliding surface and control law are the essential features of SMC as the control law tracks the system trajectory and drives the system towards sliding surface.

The SMC design starts with selecting sliding surface. As per Slotine [19], the sliding surface is given by

$$
S(t)=\left(\frac{d}{d t}+\lambda\right)^{n-1} e(t)
$$

where $\lambda$ and $n$ are the tuning parameter and order of the system, respectively. $S(t)$ represents a linear differential equation, whose unique solution is $e(t)=0$; the problem of tracking desired output is reduced by assuming $S(t)=0$. The dynamics while sliding in the surface is given by

$$
\dot{S}(t)=0
$$

Solving this equation for the control input, an expression is obtained for control input $U_{e q}$ called the equivalent control. Design of SMC for magnetic levitation is as follows.

With reference to the state space model (13), matrix representation of the system is as follows:

$$
\begin{gathered}
\left(\begin{array}{c}
\dot{x}_{1} \\
\dot{x}_{2}
\end{array}\right)=\left(\begin{array}{cc}
0 & 1 \\
-a_{0} & -a_{1}
\end{array}\right)\left(\begin{array}{l}
x_{1} \\
x_{2}
\end{array}\right)+\left(\begin{array}{l}
0 \\
1
\end{array}\right) U_{\text {in }} \\
y=[c 0]\left(\begin{array}{l}
x_{1} \\
x_{2}
\end{array}\right)
\end{gathered}
$$

where $a_{0}=981.511, a_{1}=0$ and $c=2502.96$.

(18) is simplified as

$$
y=c x_{1}
$$

and error $=$ set point - output:

$$
e_{1}=r-c x_{1}
$$

where $e_{1}$ is dynamic error, $r$ is set point and $y$ is output. (20)

Differentiating error (20) twice gives

$$
\ddot{e}_{1}=\dot{e}_{2}=a_{0}\left[r-e_{1}\right]-c U_{i n}
$$

where $e_{2}$ is the first derivative of $e_{1}(t)$ and $\dot{e}_{2}=\ddot{e}_{1}$ is the second derivative of $e_{1}(t)$.

Sliding surface of MLS $(n=2)$ is derived from (15) and after differentiation, it becomes

$$
\dot{S}(t)=\ddot{e}(t)+\lambda \dot{e}(t)=\dot{e}_{2}+\lambda e_{2} .
$$

Substituting (21) in (22) gives

$$
\dot{S}(t)=a_{0}[r-e]+\lambda \dot{e}-c U_{i n} .
$$

Solving (16), equivalent control of SMC $U_{e q}$ is (23)

$$
U_{e q}=\left(a_{0}[r-e]+\lambda \dot{e}\right) .
$$

As per Sira-Ramirez and Morales [15], SMC control law is given as

$$
u=\frac{1}{c}\left[U_{e q}+\beta s a t S(t)\right]
$$

where $\beta \geq e, \beta$ is the upperbound of disturbance, $\beta \geq a_{0} \times$ $12=981.511 \times 12$ and the operating range is $12 \mathrm{~mm}$.

$$
\operatorname{sat}(S(t))=\left\{\begin{array}{ll}
+10 V & \text { if } S(t)>0 \\
-10 V & \text { if } S(t)>0
\end{array} .\right.
$$

Voltage range fixed for analogue input and analogue output module is +10 to $-10 \mathrm{~V}$; hence the same bounds are chosen for saturation function.

Hence (23) becomes

$$
\begin{aligned}
u= & \frac{1}{2502.96}[-981.511[r-e]+\lambda \dot{e}+981.511 \\
& \times 12 \operatorname{sat}(\dot{e}(t)+\lambda e(t)) / \Phi]
\end{aligned}
$$

The control input produces chattering and it is reduced by replacing $S(t)$ by $S(t) / \Phi$ where $\Phi$ is thickness of the boundary layer in $\mathrm{V}$ and $\lambda$ is the slope; both $\Phi$ and $\lambda$ are obtained from the plot of $e(t)$ versus $d e(t) / d t$, and found to be $200 \mathrm{~V}$ and 15 , respectively.

\section{Result and discussion}

\subsection{Servo operation}

The performance characteristics are recorded for various set points within the operating range from -0.95 to $-1.50 \mathrm{~cm}$ and a comparison is made for both PID and SMC-PID controllers. Figures 2, 3, 4, 5, 6 and 7 show the system output and control input for set points $-0.95,-1.05,-1.15,-1.25,-1.35$ and $-1.45 \mathrm{~cm}$, respectively.

Ball positions for both the controllers settle quickly at $2.4 \mathrm{~s}$ but PID controller suffers from offset of about $-0.58 \mathrm{~cm}$ whereas SMC-PID is free from offset.

The response of SMC-PID controller for the set point of $-1.05 \mathrm{~cm}$ settles at $1.9 \mathrm{~s}$, which is faster than that for the set point of $-0.95 \mathrm{~cm}$; PID has no reliable offset and settling time as it keeps varying. On observing the settling time at 5,15 and $25 \mathrm{~s}$, the offset was found to be -0.61 , -0.55 and $-0.48 \mathrm{~cm}$, respectively.

The system reaches the desired position in $1.24 \mathrm{~s}$ for the hybrid controller, which is better than those of the set points -0.95 and $-1.05 \mathrm{~cm}$, and PID controller suffers from varying offset and settling time. On observing the settling 


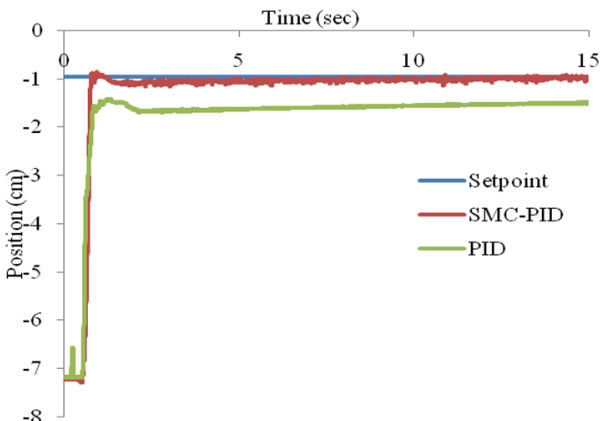

(a) System output for ball position of $-0.9 \mathrm{~cm}$.

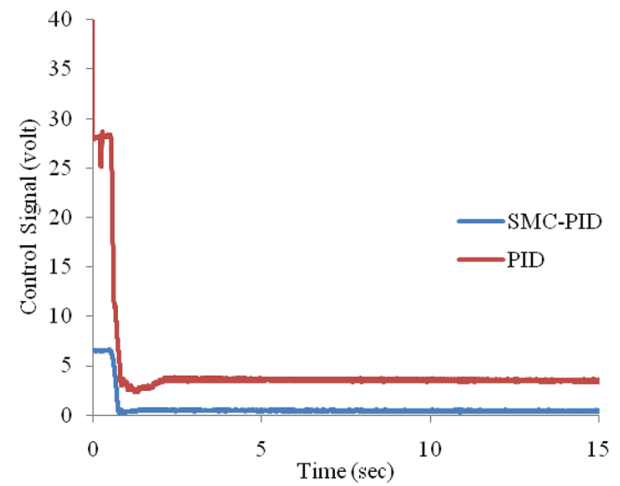

(b) Control Signal for ball position $-0.95 \mathrm{~cm}$

Figure 2. (a) System output for ball position of $-0.95 \mathrm{~cm}$. (b) Control signal for ball position of $-0.95 \mathrm{~cm}$.

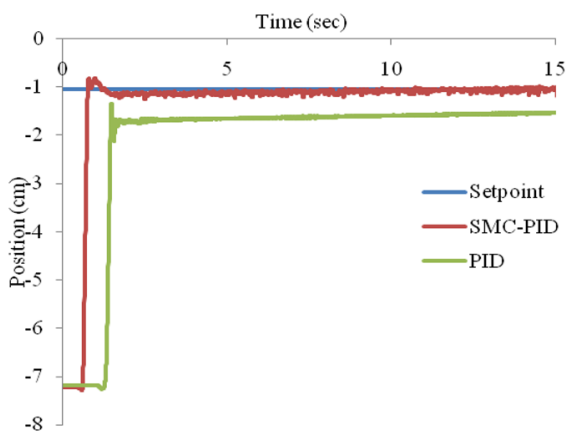

(a) System output for ball position of $-1.05 \mathrm{~cm}$.

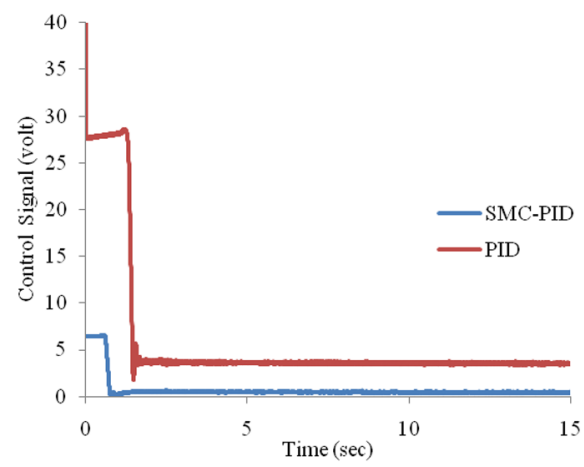

(b) Control Signal for ball position $-1.05 \mathrm{~cm}$

Figure 3. (a) System output for ball position of $-1.05 \mathrm{~cm}$. (b) Control signal for ball position of $-1.05 \mathrm{~cm}$.

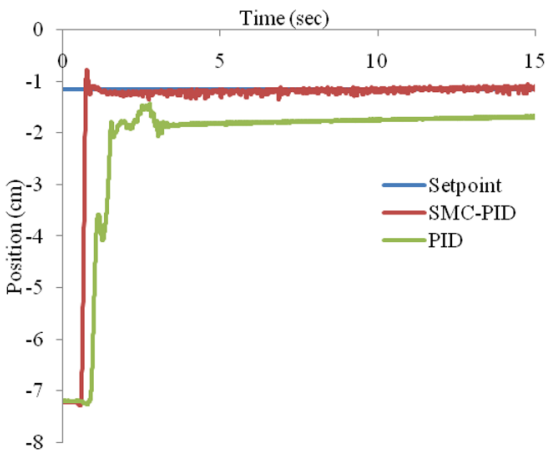

(a) System output for ball position of $-1.15 \mathrm{~cm}$.

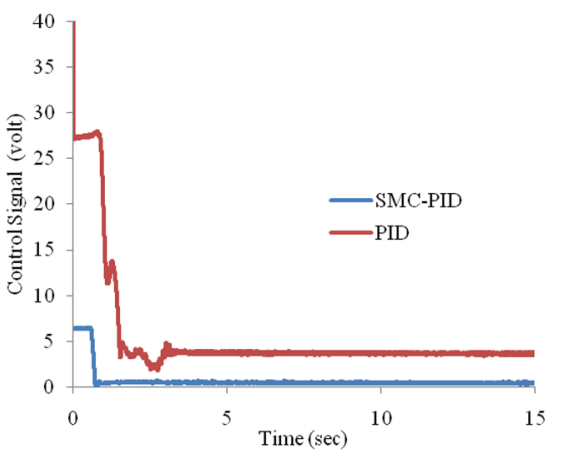

(b) Control Signal for ball position $-1.15 \mathrm{~cm}$

Figure 4. (a) System output for ball position of $-1.15 \mathrm{~cm}$. (b) Control signal for ball position of $-1.15 \mathrm{~cm}$.

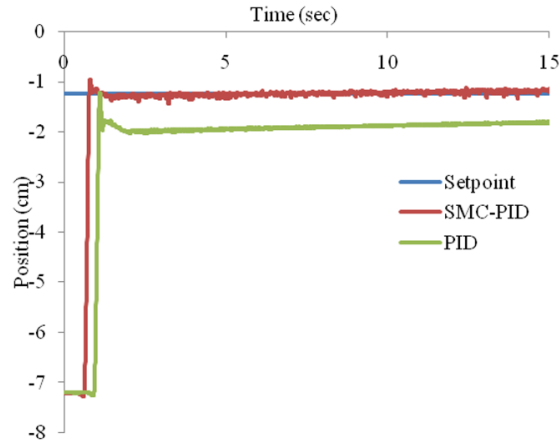

(a) System output for ball position of $-1.25 \mathrm{~cm}$.

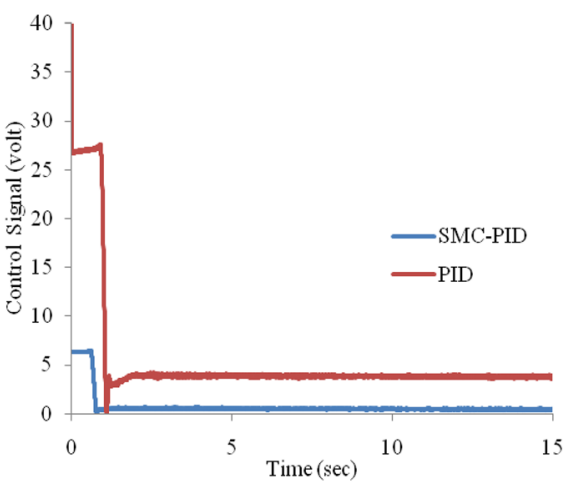

(b) Control Signal for ball position $-1.25 \mathrm{~cm}$.

Figure 5. (a) System output for ball position of $-1.25 \mathrm{~cm}$. (b) Control signal for ball position of $-1.25 \mathrm{~cm}$. 


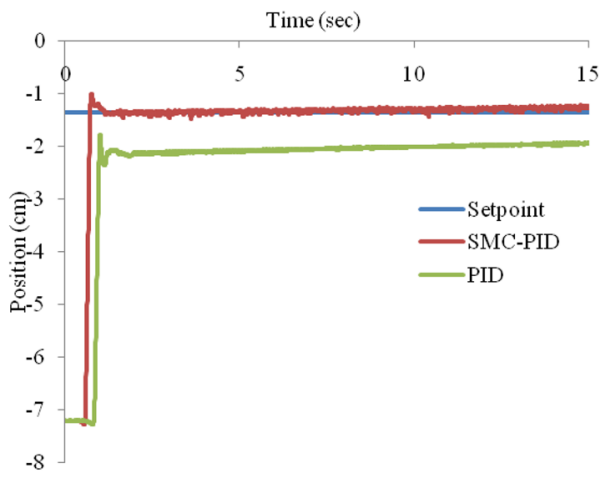

(a) System output for ball position of $-1.35 \mathrm{~cm}$.

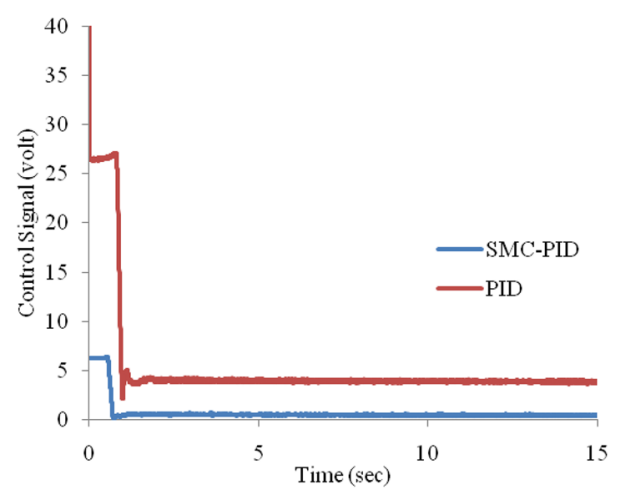

(b) Control Signal for ball position $-1.35 \mathrm{~cm}$

Figure 6. (a) System output for ball position of $-1.35 \mathrm{~cm}$. (b) Control signal for ball position of $-1.35 \mathrm{~cm}$.

time at 5,15 and $25 \mathrm{~s}$, the offset was found to be -0.67 , -0.57 and $-0.54 \mathrm{~cm}$, respectively.

The settling time for SMC-PID controller is $1.17 \mathrm{~s}$ at $-1.25 \mathrm{~cm}$; therefore, as the set point increases the settling time decreases. With respect to PID the settling time is comparatively higher and varies along with offset; thus settling time and offset are not stable for PID controller. It is known from the readings that for the settling time of 5, 15 and $25 \mathrm{~s}$, the offset is found to be $-0.71,-0.63$ and $-0.57 \mathrm{~cm}$, respectively.

The settling time for SMC-PID controller is $1.14 \mathrm{~s}$ at $-1.35 \mathrm{~cm}$. However, in PID, the settling time is comparatively higher and varies along with offset; thus settling time and offset are not stable for PID controller. It is known from the readings that for the settling time at 5,15 and $25 \mathrm{~s}$, the offset is found to be $-0.73,-0.65$ and $-0.58 \mathrm{~cm}$, respectively.

Compared with the set point range between -0.95 and $-1.35 \mathrm{~cm}$ the system reaches set point $-1.45 \mathrm{~cm}$ in $2.3 \mathrm{~s}$ even though it suffers from $38 \%$ overshoot for SMC-PID controller. The time response for PID is not appreciable as it has varying settling time and offset; as known from the readings at 5,15 and $25 \mathrm{~s}$, the offset is found to be -0.75 , -0.69 and $-0.55 \mathrm{~cm}$, respectively.

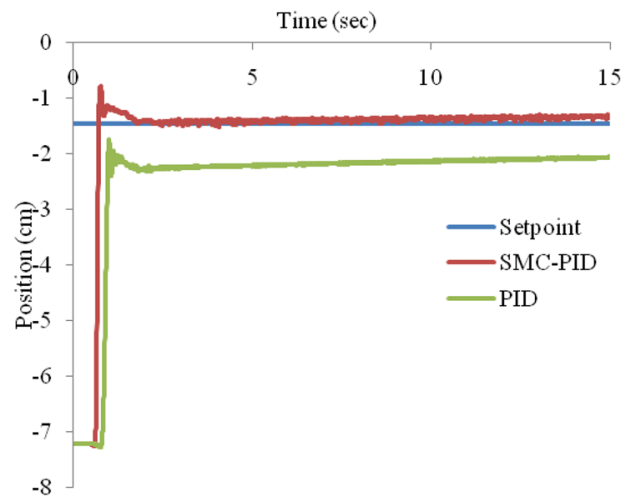

(a) System output for ball position of $-1.45 \mathrm{~cm}$.

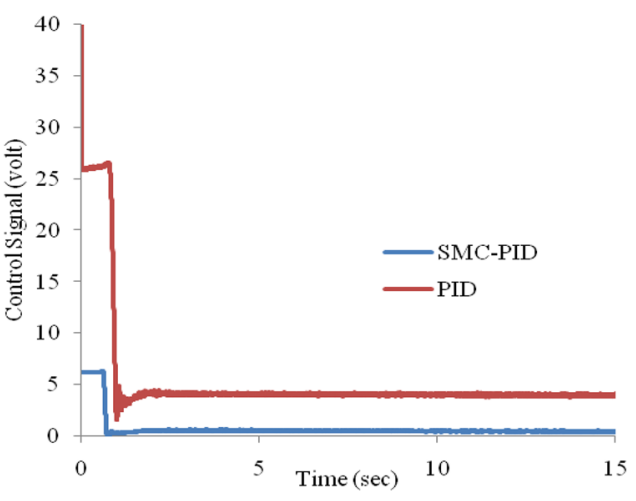

(b) Control Signal for ball position $-1.45 \mathrm{~cm}$

Figure 7. (a) System output for ball position of $-1.45 \mathrm{~cm}$. (b) Control signal for ball position of $-1.45 \mathrm{~cm}$.

SMC-PID controller proves that the nonlinear system has better performance than PID with respect to offset and settling time. It is observed that overshoot increases from $9.5 \%$ to $38 \%$ as the set point is closer to the upper limit of the operating range; however, settling time is not affected.

\subsection{Disturbance rejection}

When a disturbance is given to the MLS manually, which acts as a load to the entire system, the expected response is that the nonlinear controller rejects the disturbance and retains the ball at the original position.

The response is analysed for the two controllers at six different set points. Initially the ball is brought to the desired position and a disturbance in positive and negative direction is given at 5 and $10 \mathrm{~s}$, respectively.

Figure 8 depicts the disturbance rejection response for PID controller at various ball positions of $-0.95,-1.05$, $-1.15,-1.25,-1.35$ and $-1.45 \mathrm{~cm}$ and figure 9 shows the PID control input for the same.

It is observed from figure 8 that when the ball is manually displaced upwards towards the magnet at around $5 \mathrm{~s}$, 


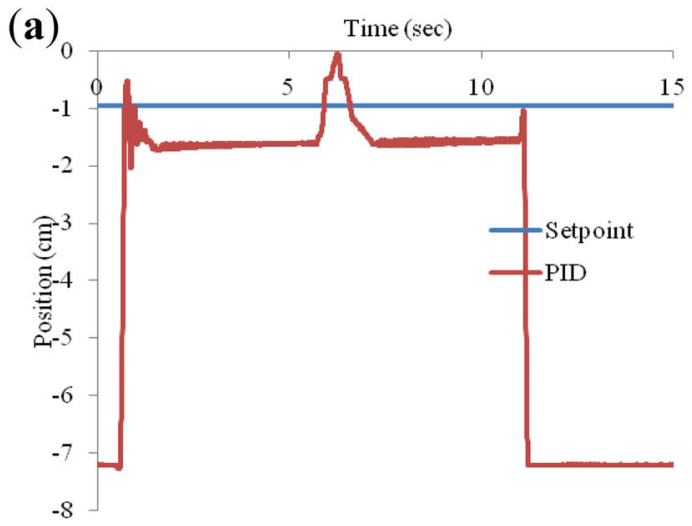

(e)
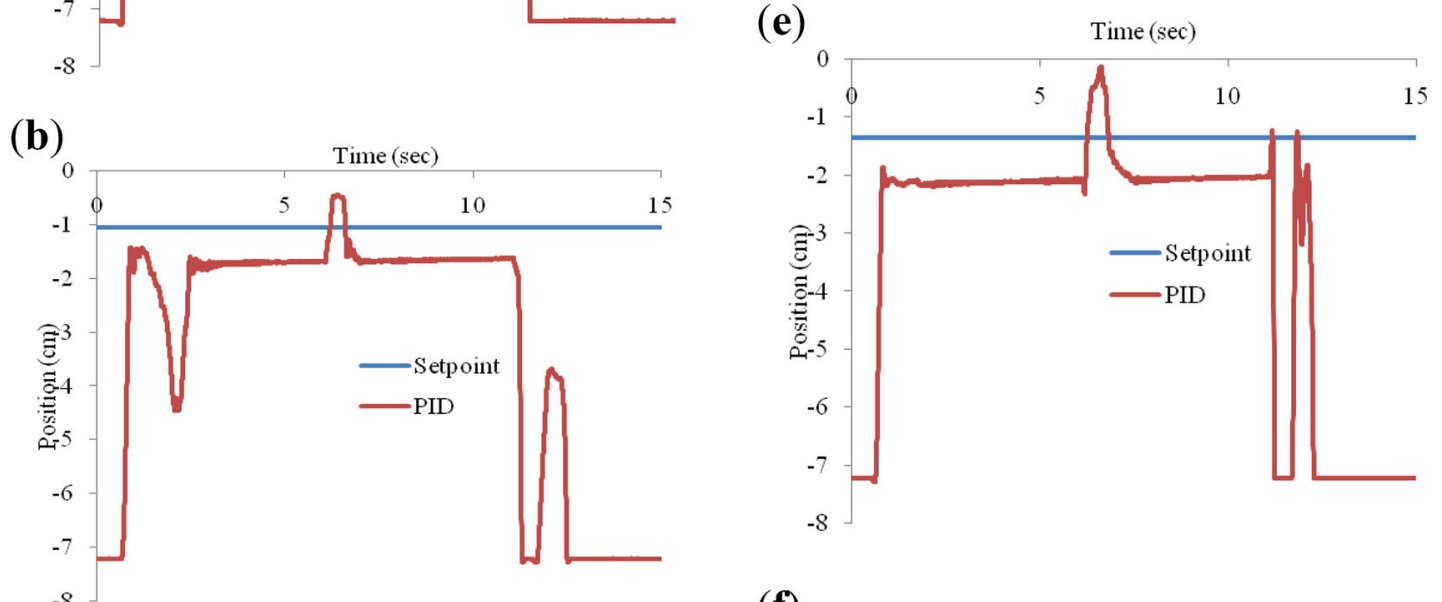

$$
-8
$$

(f)

(c)
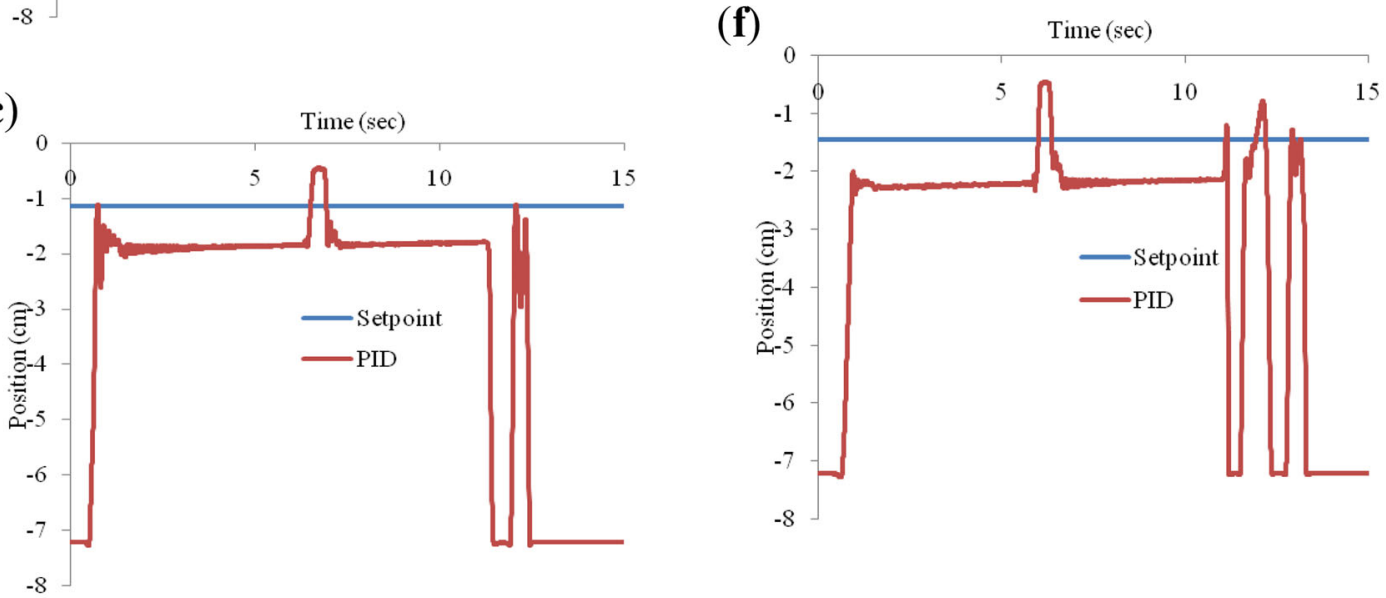

(d)

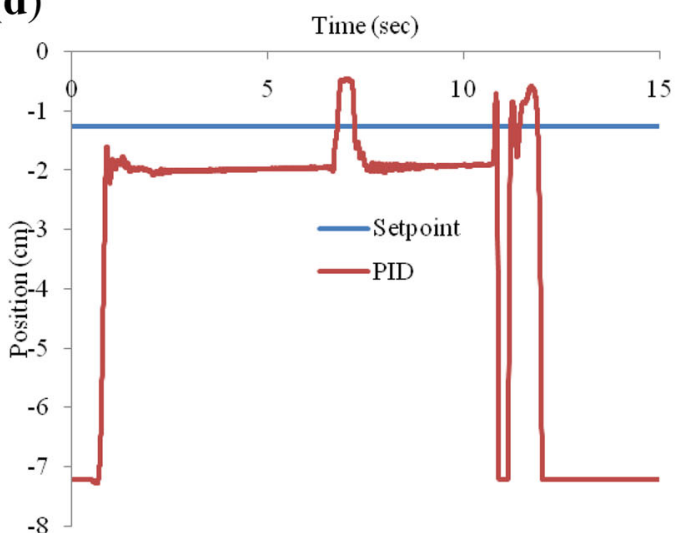

Figure 8. Disturbance rejection response for PID at (a) $-0.95 \mathrm{~cm},(\mathbf{b})-1.05 \mathrm{~cm},(\mathbf{c})-1.15 \mathrm{~cm},(\mathbf{d})-1.25 \mathrm{~cm},(\mathbf{e})-1.35 \mathrm{~cm}$ and (f) $-1.45 \mathrm{~cm}$. 

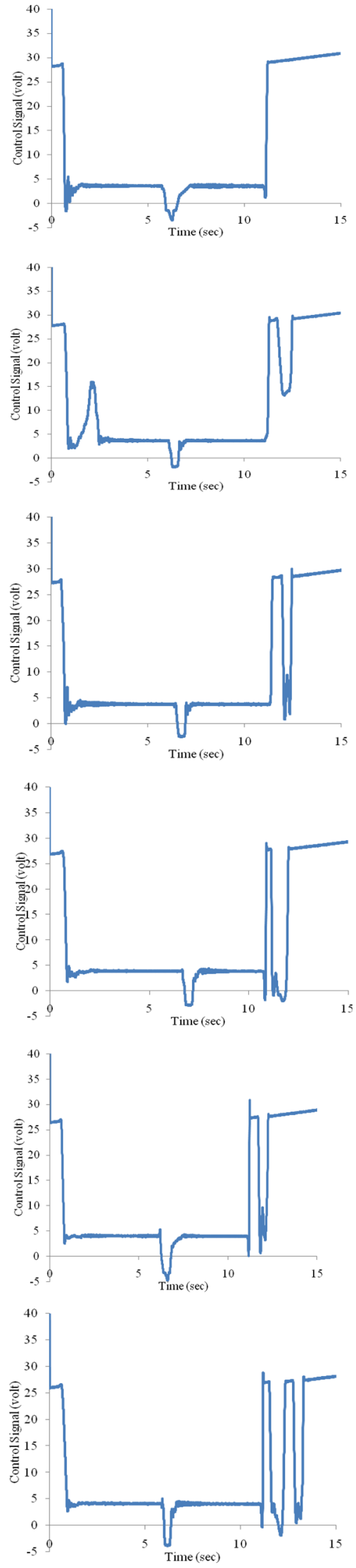

4Figure 9. PID control signal for (a) $-0.95 \mathrm{~cm},(\mathbf{b})-1.05 \mathrm{~cm}$, (c) $-1.15 \mathrm{~cm},(\mathbf{d})-1.25 \mathrm{~cm},(\mathbf{e})-1.35 \mathrm{~cm}$ and (f) $-1.45 \mathrm{~cm}$.

from the desired position where offset is default, PID controller brings the ball back to the position in $1 \mathrm{~s}$; however, when it is displaced downwards at around $10 \mathrm{~s}$, away from the magnet, the gravitational force, which is more than that of the PID controller, supersedes and hence the ball cannot be brought to the original position from where it is disturbed; as a result, the ball moved away completely from the magnet. Hence PID controller fails to achieve disturbance rejection.

It is observed from figure 10 that when the ball is displaced manually upwards and downwards at around 5 and $10 \mathrm{~s}$, from the desired position, SMC-PID controller responds to the disturbance and rejects it by bringing the ball back to the position in $1 \mathrm{~s}$. The hybrid controller supersedes both magnetic and gravitational forces. The overshoot is larger when the ball is pulled away from the magnet; however, the delay in bringing the ball back to the position is the same for both directions. Hence, SMC-PID achieves excellent disturbance rejection response (figure 11).

At the outset, it is evident, that gravitational pull overcomes the force given by the PID controller whereas in SMCPID controller the magnetic and gravitational force is balanced to actuate the ball in the desired position irrespective of the disturbances given. The results are tabulated in table 1.

Table 1 shows that SMC-PID controller is insensitive to the disturbances to a greater extent and thus achieves good regulatory response by rejecting the disturbances, which PID could not achieve.

\subsection{Set point tracking}

Whenever there is a change in set points, the nonlinear controller manipulates and responds to the set point changes. The response to the set point tracking is analysed for 4 different cases, as shown in figures 12, 13, 14, 15, $16,17,18$ and 19. Given the 2 set point changes for the figures $12,13,14$ and 15 , the set point changes are -0.95 to $-1.20 \mathrm{~cm},-0.95$ to $-1.30 \mathrm{~cm}$ and -0.95 to $-1.40 \mathrm{~cm}$. However, for figures 16, 17, 18 and 19, there are 3 set point changes: -0.95 to -1.20 and $-1.40 \mathrm{~cm}$.

Figures 12 and 13 show the response of set point tracking for PID controller and control inputs for 2 set point changes given at 0 and $5 \mathrm{~s}$, respectively. It is observed that PID controller cannot track the set point change and as a result the ball is pulled away from the magnet by the gravitational force.

Figures 14 and 15 show the response of set point tracking for SMC-PID controller and control inputs for 2 set point changes given at 0 and $5 \mathrm{~s}$, respectively. It is observed that SMC-PID controller efficiently tracks the set point change and without a delay by superseding the 

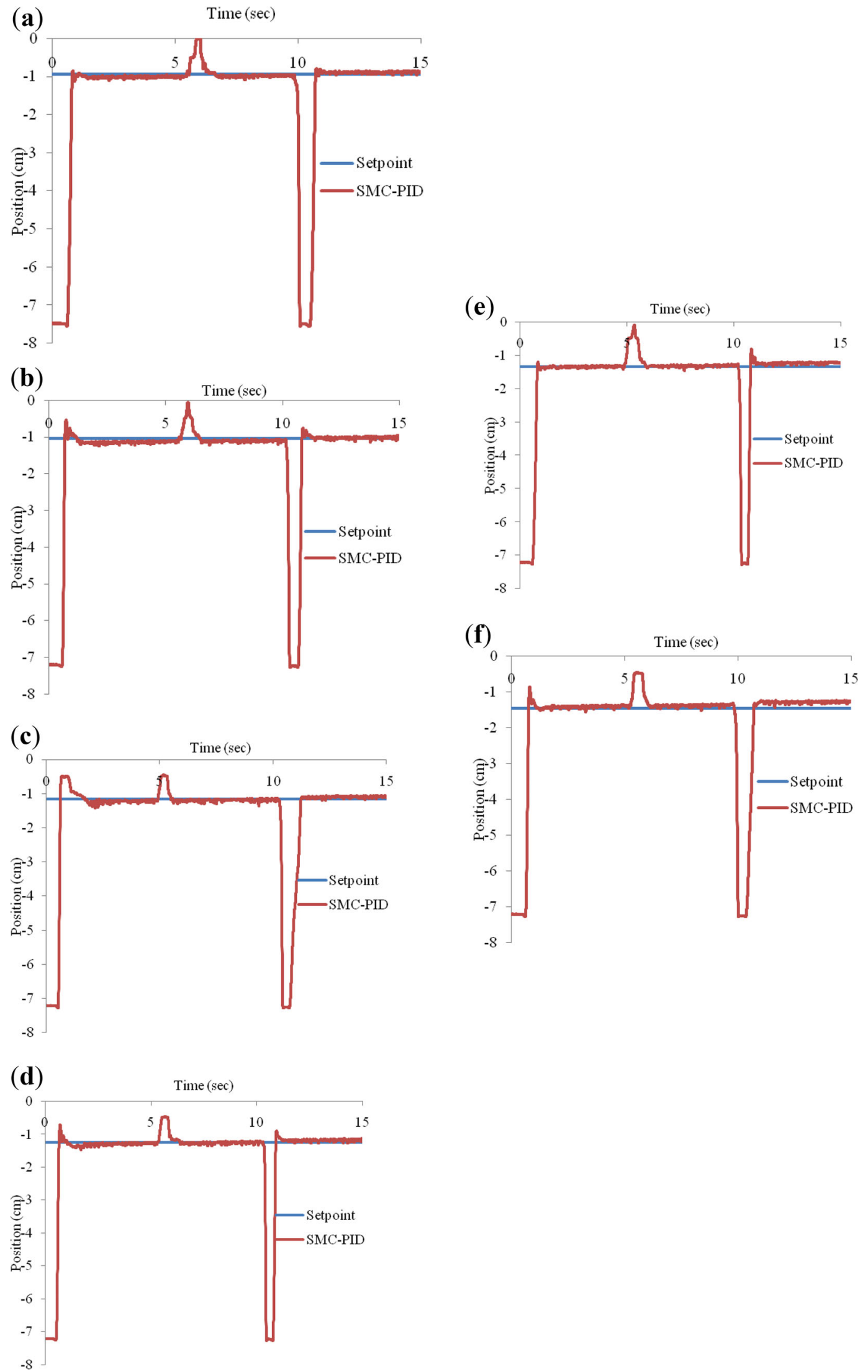

Figure 10. Disturbance rejection response for SMC-PID at (a) $-0.95 \mathrm{~cm},(\mathbf{b})-1.05 \mathrm{~cm},(\mathbf{c})-1.15 \mathrm{~cm},(\mathbf{d})-1.25 \mathrm{~cm},(\mathbf{e})-1.35 \mathrm{~cm}$ and (f) $-1.45 \mathrm{~cm}$. 


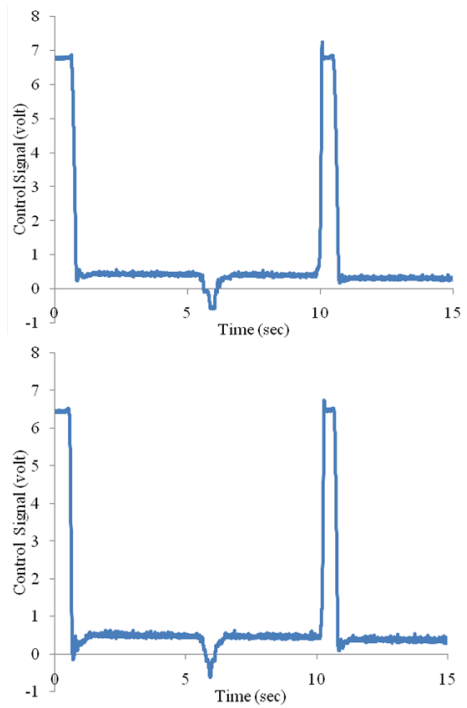

Table 1. Settling time of controllers.

\begin{tabular}{|c|c|c|c|c|}
\hline \multirow[b]{2}{*}{$\mathrm{SP}(\mathrm{cm})$} & \multicolumn{2}{|c|}{ PID } & \multicolumn{2}{|c|}{ SMC-PID } \\
\hline & $\begin{array}{c}+\mathrm{ve} \\
\text { direction } \\
\text { (s) }\end{array}$ & $\begin{array}{c}\text {-ve direction } \\
\text { (s) }\end{array}$ & $\begin{array}{c}\text { +ve } \\
\text { direction } \\
\text { (s) }\end{array}$ & $\begin{array}{c}-\mathrm{ve} \\
\text { direction (s) }\end{array}$ \\
\hline-0.95 & 1.35 & $\infty$ & 0.89 & 1.03 \\
\hline-1.05 & 1.03 & $\infty$ & 0.90 & 0.80 \\
\hline-1.15 & 0.98 & $\infty$ & 0.70 & 1.10 \\
\hline-1.25 & 1.02 & $\infty$ & 0.90 & 0.78 \\
\hline-1.35 & 1.20 & $\infty$ & 0.91 & 0.88 \\
\hline-1.45 & 1.02 & $\infty$ & 0.90 & 1.10 \\
\hline
\end{tabular}

(a) -0.95 and $-1.20 \mathrm{~cm}$
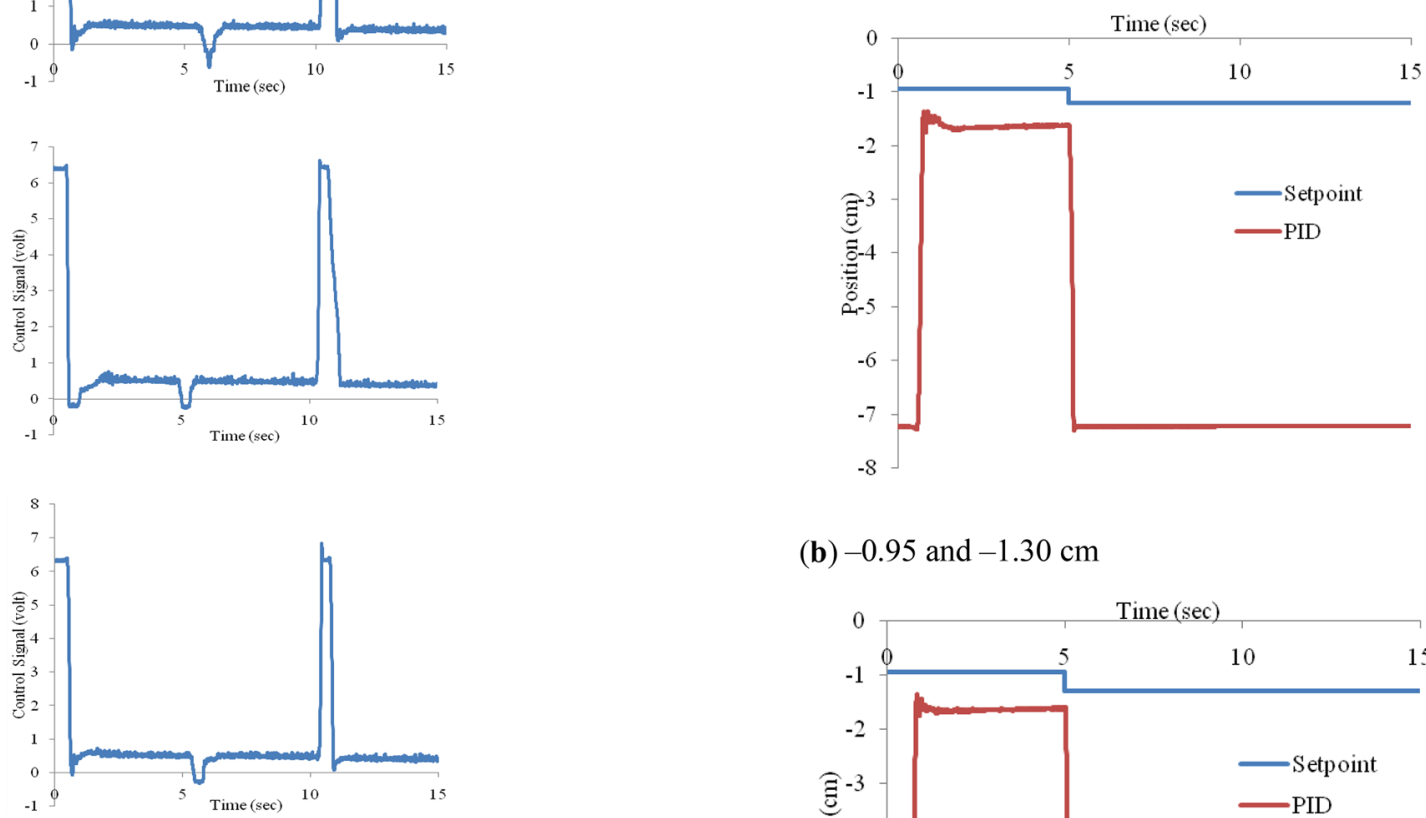

(b) -0.95 and $-1.30 \mathrm{~cm}$

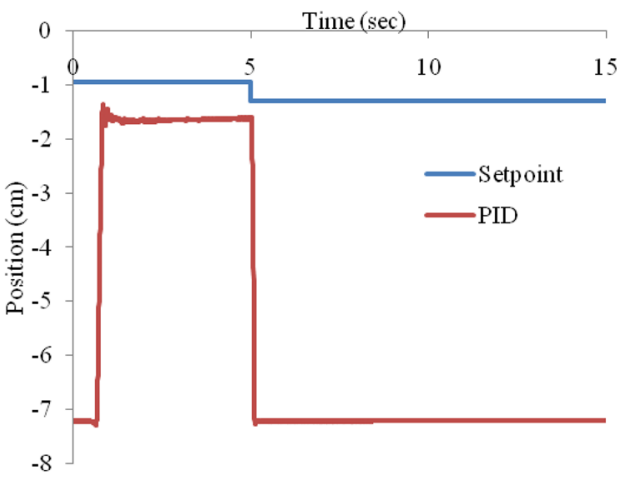

(c) -0.95 and $-1.40 \mathrm{~cm}$

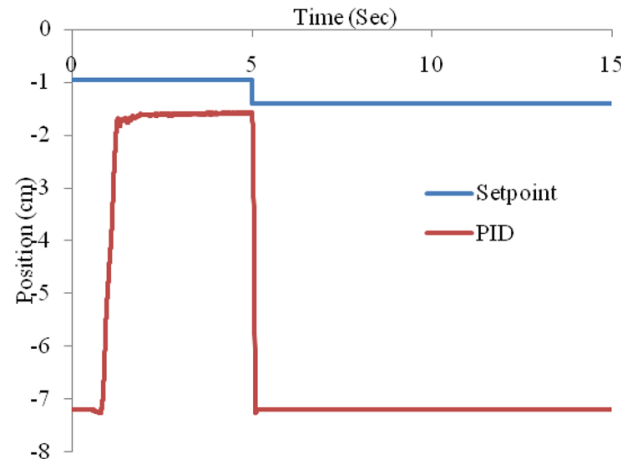

Figure 11. SMC-PID control signal for (a) $-0.95 \mathrm{~cm}$, (b) $-1.05 \mathrm{~cm}$, (c) $-1.15 \mathrm{~cm}$, (d) $-1.25 \mathrm{~cm}$, (e) $-1.35 \mathrm{~cm}$ and (f) $-1.45 \mathrm{~cm}$.

Figure 12. PID response for two set point changes. 

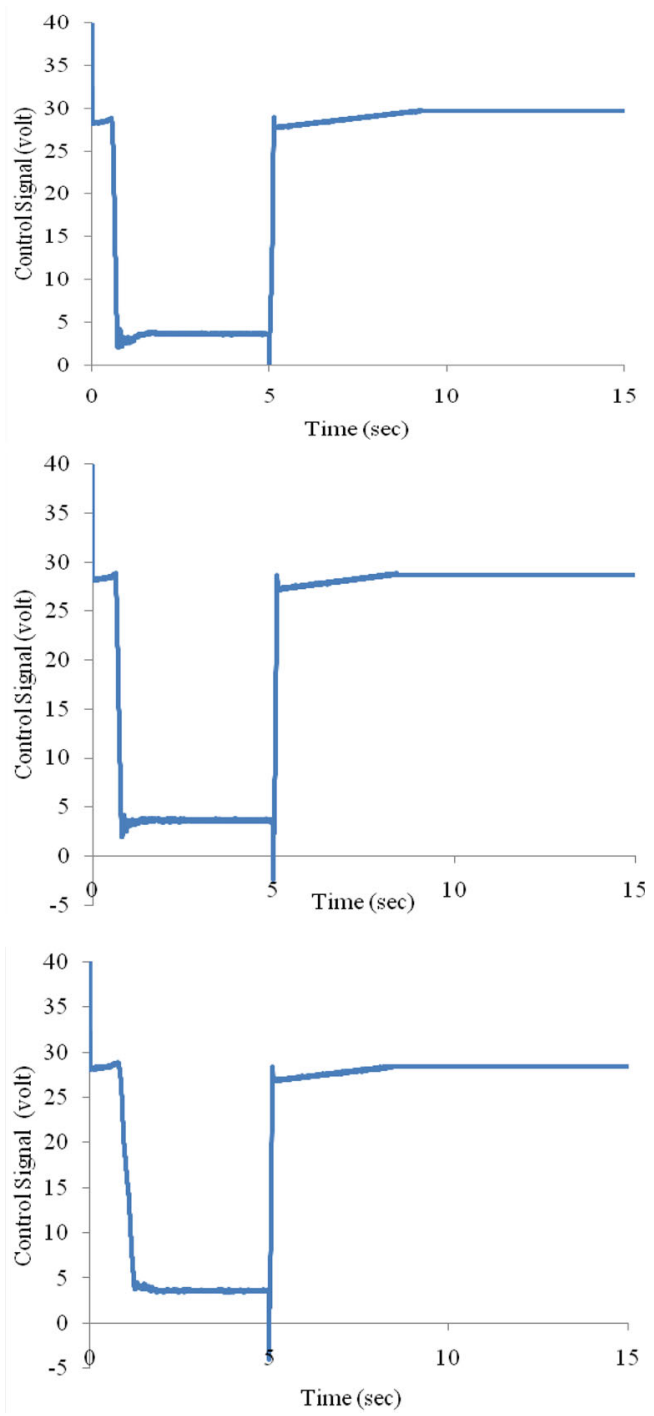

Figure 13. PID control signal for two set point changes.

gravitational pull. Hence, SMC-PID achieves excellent set point tracking.

Figures 16 and 17 show the response of set point tracking for PID controller and control inputs for 3 set point changes given at 0,5 and $10 \mathrm{~s}$, respectively. It is observed that PID controller fails to track the set point change and as a result it has been pulled by the gravitational force away from the magnet.

Figures 18 and 19 show the response of set point tracking for SMC-PID controller and control inputs for 3 set point changes given at 0,5 and $10 \mathrm{~s}$, respectively. It is observed that SMC-PID controller is successful in tracking the set point changes and it has overcome both magnetic force and the gravitational force without a time delay.

It is summarized that for the first set point change the PID controller acts abruptly; however, for such set points
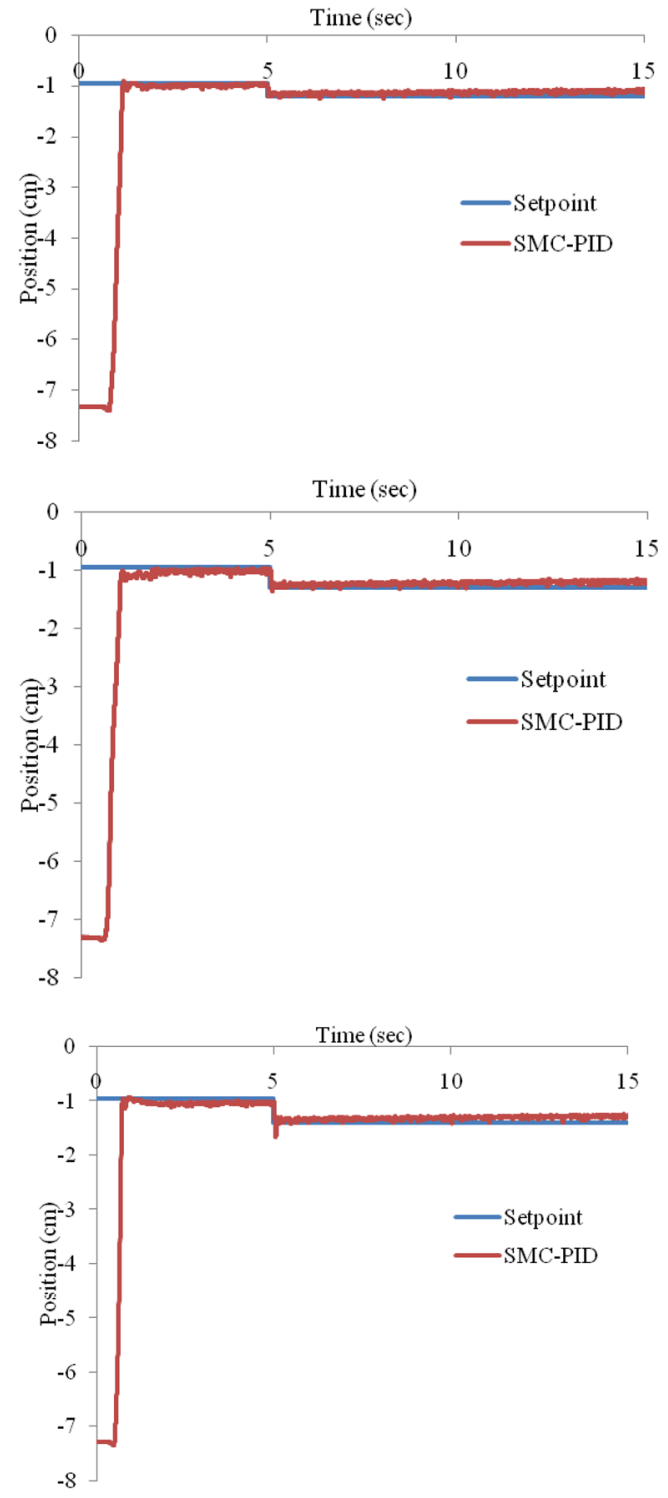

Figure 14. SMC-PID response for two set point changes.

the SMC controller responds effectively to the set point change. These plots show that SMC-PID controller supports set point tracking with minimal time of sensitiveness to the changes in the response and thus the controller achieves good servo response; however, PID controller fails to respond to the changes.

\section{Conclusion}

The laboratory set-up of MLS is analysed, for which a nonlinear robust controller is designed for the system. The experimental results were extracted and compared to the performance of the PID and SMC-PID controllers for the given system. On experimenting, it is observed that the PID 

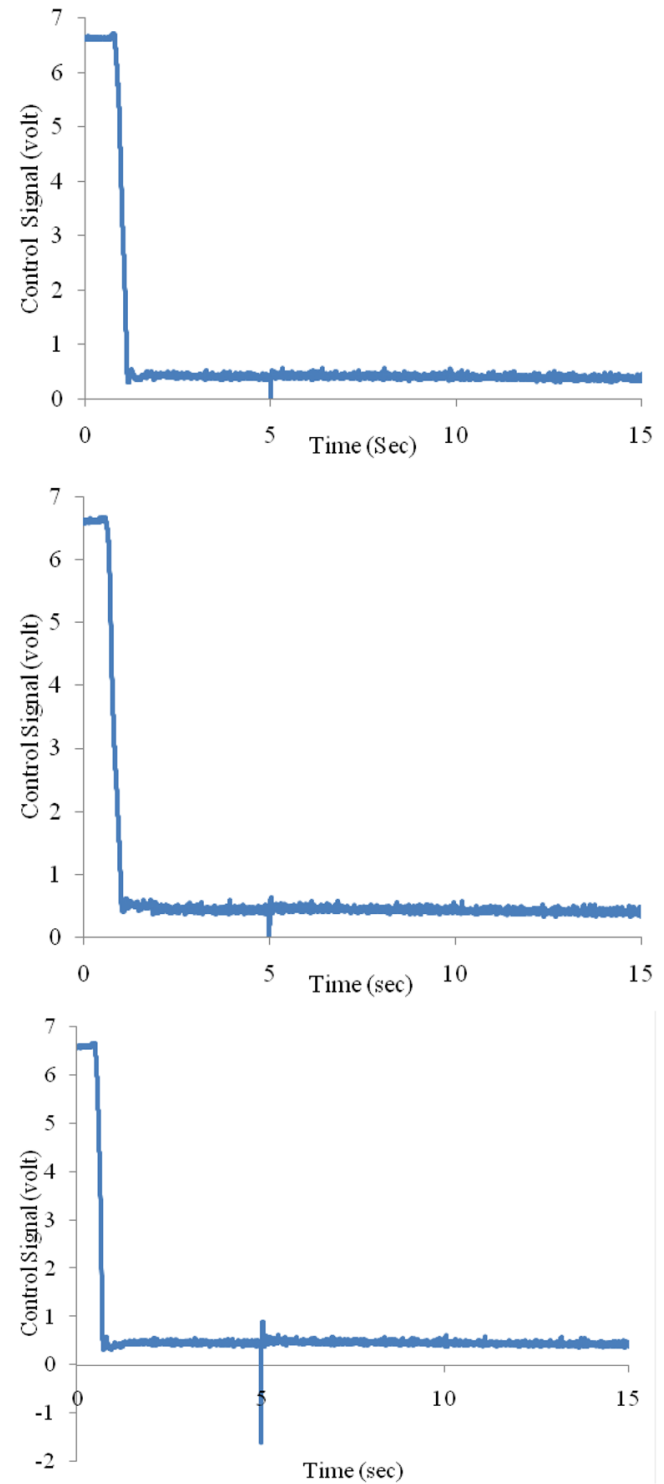

Figure 15. SMC-PID control signal for two set point changes.

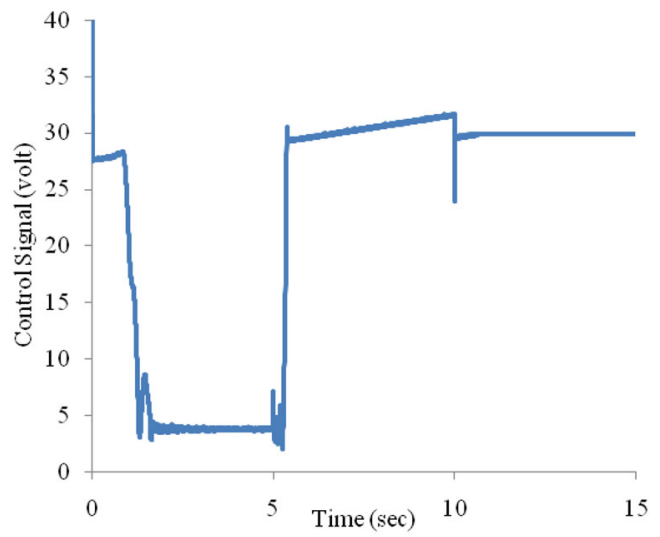

Figure 17. PID control signal for 3 set point changes of -1.2 , -1.00 and $-1.40 \mathrm{~cm}$.

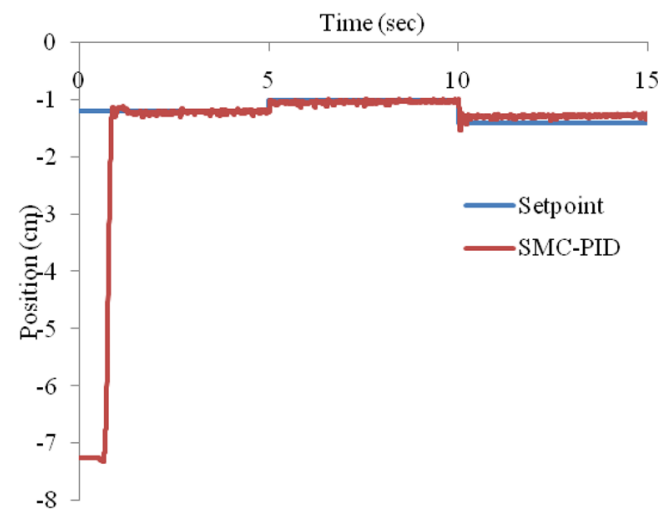

Figure 18. SMC-PID response for 3 set point changes of -1.2 , -1.00 and $-1.40 \mathrm{~cm}$.

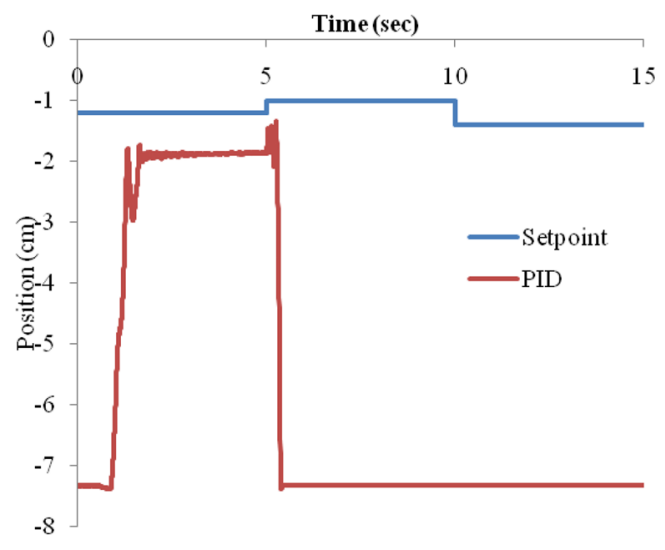

Figure 16. PID response for 3 set point changes of $-1.2,-1.00$ and $-1.40 \mathrm{~cm}$.

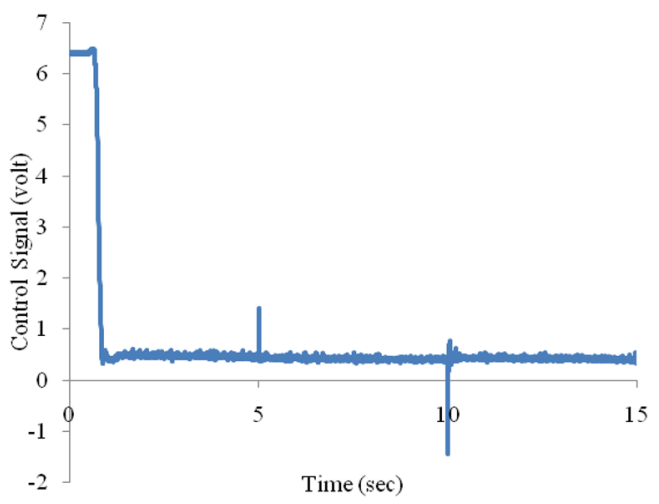

Figure 19. SMC-PID control signal for 3 set point changes of $-1.2,-1.00$ and $-1.40 \mathrm{~cm}$. 
controller shows unstable offset and settling time whereas nonlinear controller's response is free from offset and ensures minimum settling time; hence it reaffirms the good performance. The robustness of the system is examined by conducting a test on disturbance rejection and set point tracking. The results prove that the designed SMC-PID controller achieves excellence in disturbance rejection and also it is insensitive to set point changes. Furthermore, the design of SMC-PID controller is free from chattering problem. The given laboratory set-up has minimum operating range from -0.95 to $-1.45 \mathrm{~cm}$; however, the design can be applied for wider ranges.

\section{References}

[1] Wai R J and Lee J D 2009 Robust levitation control for linear Maglev rail system using fuzzy neural network. IEEE Transactions on Control Systems Technology 17(1): 4-14

[2] $\mathrm{Yu} \mathrm{W}$ and $\mathrm{Li}$ X 2014 A magnetic levitation system for advanced control education. In: Proceedings of the 19th International Federation of Automatic Control World Congress, Cape Town, South Africa, pp. 24-29

[3] Khamesee M B, Kato N, Nomura Y and Nakamura T 2002 Design and control of a microrobotic system using magnetic levitation. IEEE/ASME Transactions on Mechatronics 7(1): 1-14

[4] Knospe C R and Collins E G 1996 Introduction to the Special issue on magnetic bearing control. IEEE Transactions on Control Systems Technology 4(5): 481

[5] Higuchi T, Bang Y B, Motegi Y and Tsuda M 1999 Automation of centered micro hole drilling using a magnetically levitated table. International Journal of Machine Tools and Manufacture 39: 1409-1426

[6] Walter H, Arsac S, Bock J, Siems S O, Canders W R, Leenders A, Freyhardt H C, Fieseler H and Kesten M 2003 Liquid hydrogen tank with cylindrical superconducting bearing for automotive application. IEEE Transactions on Applied Superconductivity 13: 2

[7] Baptiste L, Landschoot N v, Gleijm G, Priede J, Westrum J S v, Velthuis H and Kim T Y 2007 Electromagnetic levitation: a new technology for high rate physical vapour deposition of coatings onto metallic strip. Surface and Coatings Technology 202: 1189-1193

[8] Celik S 2016 Design of magnetic levitation force measurement system at any low temperatures from $20 \mathrm{~K}$ to room temperature. Journal of Alloys and Compounds 662: 546-556

[9] Hasirci U, Balikci A, Zabar Z and Birenbaum L 2011 A novel magnetic levitation system: design, implementation, and nonlinear control. IEEE Transactions on Plasma Science 39: 1

[10] Hajjaji A E and Guladsine M 2001 Modeling and nonlinear control of magnetic levitation system. IEEE Transaction on Industrial Electronics 48(4): 831-838

[11] Shameli E, Khamesee M B and Huissoon J P 2008 Real-time control of a magnetic levitation device based on instantaneous modeling of magnetic field. Mechatronics 18: $536-544$

[12] Dukaa A V, Dulua M and Oltean S E 2016 IMC based PID control of a magnetic levitation system. Procedia Technology 22: 592-599

[13] Yang J, Sun R, Cui J and Ding X 2004 Application of composite fuzzy-PID algorithm to suspension system of maglev train. In: Proceedings of the 30th Annual Conference of the IEEE Industrial Electronics Society, vol. 3

[14] Milani R H, Zarabadipour H and Shahnazi R 2012 An adaptive robust controller for time delay maglev transportation systems. Communications in Nonlinear Science and Numerical Simulation 17: 4792-4801

[15] Folea S, Muresan C I, Keyser R D and Ionescu C M 2016 Theoretical analysis and experimental validation of a simplified fractional order controller for a magnetic levitation system. IEEE Transactions on Control Systems Technology 24: 2

[16] Swain S K, Sain D, Mishra S K and Ghosh S 2017 Real time implementation of fractional order PID controllers for a magnetic levitation plant. International Journal of Electronics and Communications 78: 141-156

[17] Wong T H 1986 Design and levitation of a magnetic levitation control system-an undergraduate project. IEEE Transaction on Education 29(4): 196-200

[18] Sira-Ramirez H and Morales R 2010 Trajectory tracking for the magnetic ball levitation system via exact feed forward linearization and GPI control. International Journal of Control 83(6): 1155-1166.

[19] Slotine J J E and Li W 1991 Applied nonlinear control. New Jersey: Prentice-Hall 